\title{
Impedance cardiography - optimization and efficacy evaluation of antihypertensive treatment
}

\author{
KATARZYNA PANASIUK-KAMIŃSKAA-F, JOLANTA SZELIGA-KRÓL ${ }^{A-F}$, RENATA ZUBILEWICZ ${ }^{A-F}$, \\ ANDRZEJ JAROSZYŃSKIA
}

Department of Family Medicine, Medical University of Lublin

A - Study Design, B - Data Collection, C - Statistical Analysis, D - Data Interpretation, E - Manuscript Preparation,

$\mathbf{F}$ - Literature Search, $\mathbf{G}$ - Funds Collection

Summary Background. Hypertension is a civilization disease which currently affects about $10.5 \mathrm{~m}$ people in Poland. The number of patients with diagnosed, untreated hypertension amounts to $18 \%$, and as many as $45 \%$ of patients are treated ineffectively, whereas only $26 \%$ are treated effectively. Impedance cardiography (IC) is an important tool both in diagnostics and the treatment of hypertensive patients, particularly in the case of antihypertensive treatment resistance. This method allows for the individualized treatment of each patient on the basis of hemodynamic parameters, monitoring of hypertensive patients in the outpatient care setting, and the assessment of cardiovascular risk factors.

Objectives. The aim of the study was to evaluate the efficacy of hypotensive medications in patients with hypertension using impedance cardiography.

Material and methods. The study involved 60 hypertensive patients, treated with antihypertensives, who failed to achieve the required blood pressure values. The modification of hypertension therapy was based on EBM (evidence-based medicine) and on hemodynamic parameters obtained using impedance cardiography.

Results. It was found that high blood pressure therapy based on impedance cardiography parameters has a significant influence on blood pressure reduction compared to EMB-based therapy: below 140/90: 66.8 vs. 55.1\% and below 130/80: 23.5 vs. $18.9 \%$.

Conclusions. On the basis of this study it was confirmed that impedance cardiography allows for a significant reduction of hypertension and the selection of the most effective therapeutic strategy, providing for the optimization and efficacy of hypertension treatment.

Key words: hypertension, impedance cardiography, EBM.

\section{Background}

Hypertension is a civilization disease which currently affects about $972 \mathrm{~m}$ people all over the world, including 10.5 $\mathrm{m}$ in Poland [1-3].

In Poland, the number of patients with diagnosed, untreated hypertension amounts to $18 \%$, and as many as $45 \%$ of patients are treated ineffectively, whereas only $26 \%$ are treated effectively. It is estimated that every year $14 \%$ of deaths in the world are caused by hypertension. Therefore, it is very important to diagnose this disease entity properly and as early as possible, and following that, to treat it effectively [3, 4].

Particular attention must be paid to the very issue of hypertension treatment, considering all its benefits while being aware and taking into account all the adverse effects of individual medications. This is of crucial importance for the optimization and efficacy of hypertension treatment $[5,6]$.

The new methods for monitoring the hemodynamic parameters of the cardiovascular system have recently become objects of scientific interest. Presently, impedance cardiography, IC, is used in cardiology practice, allowing for the precise evaluation of such parameters as: cardiac output, systemic vascular resistance, vascular stiffness, left ventricular ejection time [7-10].

\section{Objectives}

The aim of the study was to evaluate the efficacy of hypotensive medications in patients with hypertension using impedance cardiography.

\section{Material and methods}

The examination was performed at the "Zdrowie" GP practice in Lublin in 60 patients with hypertension. Patients with diagnosed hypertension $(\geq 140 / 90)$ who were not treated before, and patients treated with one or more hypotensive drugs, who failed to achieve the required values, were qualified for the study.

The exclusion criteria were as follows: secondary hypertension, improperly controlled hypertension treated with three or more hypotensive drugs, concomitant morbidities, such as: cardiac diseases, cardiomyopathies, significant cardiac rhythm disturbance, vascular diseases, renal diseases, COPD, diabetes, polyneuropathy, peripheral vascular disease, age $<18$ years and $>65$ years.

The study was approved by the Bioethical Committee at the Medical University of Lublin. No. of approval: KE$-0254 / 121 / 2011$. All patients provided their written informed consent to participate in the study. 
The study population of patients was randomly divided into two groups. The study was conducted in a randomized manner. Each group of patients included 30 subjects. The first group consisted of patients in whom the modification of hypertension treatment was based on EBM (evidence-based medicine). The second group consisted of patients in whom the modification of hypertension treatment was based on the hemodynamic parameters obtained by impedance cardiography (Table 1). The test was performed using the Icon bioimpedance analyzer, Osypka.

\begin{tabular}{|l|l|l|l|}
\hline \multicolumn{4}{|c|}{ Table 1. Characteristics of two groups of patients } \\
\hline & EBM patients & IC patients & $p$ \\
\hline Women & $\begin{array}{l}18(60 \% \text { of the } \\
\text { total number of } \\
\text { patients) }\end{array}$ & $\begin{array}{l}21(70 \% \text { of the } \\
\text { total number of } \\
\text { patients) }\end{array}$ & 0.313 \\
\hline Men & $\begin{array}{l}12(40 \% \text { of the } \\
\text { total number of } \\
\text { patients) }\end{array}$ & $\begin{array}{l}9(30 \% \text { of the } \\
\text { total number of } \\
\text { patients) }\end{array}$ & 0.284 \\
\hline Age & $55.2 \pm 8.86$ & $52.7 \pm 9.07$ & 0.412 \\
\hline BMI & $26.96 \pm 12.17$ & $28.31 \pm 12.26$ & 0.298 \\
\hline
\end{tabular}

An attending physician performed a blood pressure measurement (the mean value of 3 measurements) using Tensoval, Hartmann's upper arm blood pressure monitor.

Impedance cardiography examination was performed 3 times: on the first appointment, after one month, and after two months since the first appointment.

For the evaluation of hypertension treatment efficacy, as well as its modification, the following parameters were employed [1]: $\mathrm{Cl}$ (cardiac index) for hyperdynamic profile, where $\mathrm{Cl}>4,2 \mathrm{~L} / \mathrm{min} / \mathrm{m}^{2}$ and/or HR > 80/min: beta blocker; SVRI (systemic vascular resistance index) for vasoconstriction profile, where SVRI $>2500 \mathrm{dyn} \cdot \mathrm{s} \cdot \mathrm{cm}^{-5} \cdot \mathrm{m}^{2}$ : ACEI or ARB, at SVRI > 2800: Ca channel blocker; TFC (thoracic fluid content) for hypervolemic profile, where TFC > 34 1/ kOhm for men and > 24 1/kOhm for women: diuretic.

On the first appointment the hypotensive treatment was modified based on EBM or hemodynamic data of impedance cardiography.

Medications which were used for hypotensive treatment modification were as follows [1]: ACEI: lisinopril, ARB: telmisartan, tiasis diuretic: hydrochlorothiazide, beta blocker: metoprolol, Ca channel blocker: amlodipine.

At the next two appointments the efficacy of hypotensive treatment was evaluated on the basis of RR measurements and hemodynamic parameters of impedance cardiography. Another stage involved a comparison of the results obtained in the two groups of patients.

\section{Statistical evaluation}

The obtained study results were statistically analyzed. The analysis was performed using the Statistica 10 package. For comparison of the two groups, in which the distribution was not significantly different from the normal one, statistical significance was verified using the $t$-Student test for independent samples, and the $U$ Mann-Whitney test was used for the distributions which were significantly different from the normal one. To verify the significance of differences for time effects ( 3 stages of the study) in the case of normal distribution a single factor ANOVA analysis of variance was employed for repeated measures (with the Greenhouse-Geisser correction if the sphericity assumptions were not met) or multivariate ANOVA for repeated measures (the Wilks test). If the normality assumptions were not met, ANOVA Freidman's nonparametric test was used to compare time effects. The significance level was determined at $p=0.05$.

\section{Results}

\begin{tabular}{l} 
Table 2. Quantitative distribution of applied drug groups \\
in study groups \\
\hline
\end{tabular}

Table 3. Comparison of study results in two groups of patients

\begin{tabular}{|c|c|c|c|}
\hline & EBM patients & IC patients & $p$ \\
\hline \multicolumn{4}{|c|}{ 1st measurement } \\
\hline SBP & $138.3 \pm 12.6$ & $155.3 \pm 7.6$ & 0.000 \\
\hline DBP & $79.5 \pm 6.4$ & $87.5 \pm 8.3$ & 0.000 \\
\hline SVRI & $2539.0 \pm 396.3$ & $2791.5 \pm 548.9$ & 0.046 \\
\hline $\mathrm{Cl}$ & $3.2 \pm 0.6$ & $3.4 \pm 0.6$ & 0.027 \\
\hline $\mathrm{HR}$ & $73.7 \pm 8.4$ & $75.9 \pm 9.1$ & 0.337 \\
\hline TFC & $25.8 \pm 5.4$ & $27.7 \pm 3.0$ & 0.004 \\
\hline
\end{tabular}

\section{2nd measurement}

\begin{tabular}{|l|l|l|l|}
\hline SBP & $140.3 \pm 11.4$ & $139.3 \pm 12.0$ & 0.742 \\
\hline DBP & $81.9 \pm 8.0$ & $83.6 \pm 7.6$ & 0.402 \\
\hline SVRI & $2751.1 \pm 593.8$ & $2603.7 \pm 446.7$ & 0.282 \\
\hline CI & $3.3 \pm 0.5$ & $3.2 \pm 0.4$ & 0.918 \\
\hline HR & $73.6 \pm 8.7$ & $75.2 \pm 8.2$ & 0.252 \\
\hline TFC & $26.8 \pm 6.0$ & $27.1 \pm 2.7$ & 0.077 \\
\hline
\end{tabular}

\section{3rd measurement}

\begin{tabular}{|l|l|l|l|}
\hline SBP & $134.3 \pm 12.6$ & $131.1 \pm 12.0$ & 0.018 \\
\hline DBP & $80.0 \pm 6.0$ & $79.5 \pm 6.4$ & 0.040 \\
\hline SVRI & $2571.4 \pm 598.3$ & $2539.0 \pm 396.3$ & 0.037 \\
\hline Cl & $3.2 \pm 0.6$ & $3.1 \pm 0.4$ & 0.712 \\
\hline HR & $73.7 \pm 8.4$ & $73.2 \pm 7.9$ & 0.838 \\
\hline TFC & $25.8 \pm 5.4$ & $24.4 \pm 3.3$ & 0.425 \\
\hline
\end{tabular}

At the 0.05 level of significance a statistically significant difference was observed between SBP-1 ( $p=0.000)$, DBP-1 $(p=0.000)$ and SVRI-1 $(p=0.046)$ values obtained in the EBM and IC groups.

At the 0.05 level of significance a statistically significant difference was observed between $\mathrm{Cl}-1(p=0.027)$, TFC-1 $(p=0.004)$ values obtained in the EBM and IC groups.

At the 0.05 level of significance a statistically significant difference was observed between SBP-3 $(p=0.018)$, DBP-3 $(p=0.040)$ and SVRI-3 $(p=0.037)$ values obtained in the EBM and IC groups (Table $2-4)$.

Table 4. Efficacy of hypertension treatment in two groups of patients - percentage distribution

\begin{tabular}{|l|l|l|l|}
\hline & EBM patients & IC patients & $\boldsymbol{p}$ \\
\hline$<140 / 90$ & $55.1 \%$ & $66.8 \%$ & 0.046 \\
\hline$<130 / 80$ & $18.9 \%$ & $23.5 \%$ & 0.030 \\
\hline
\end{tabular}

\section{Discussion}

Hypertension is one of the most common cardiovascular diseases. Previous research analyses indicate that the appropriate values of blood pressure significantly decrease the 
risk of further disease progression and prevent the relevant complications. Bearing that in mind, an early diagnosis and constant, effective monitoring of hypertension has become an indispensable practice conditioning patients' quality of life $[1,11]$.

Impedance cardiography (IC) is a method which allows for a precise determination of the initial cause of hypertension, and in consequence, for the selection of the most optimal scheme of treatment $[12,13]$.

Smith et al. [14] proved that hypertension treatment based on the hemodynamic parameters of impedance cardiography, such as: SVRI, TFC and $\mathrm{Cl}$, has a significant influence on the reduction of blood pressure. Similar results were obtained in this study. It was indicated that, similarly to Smith et al. [14], the values of hypertension significantly decreased, below 140/90: 66.8 vs. $55.1 \%$, and below 130/80: 23.5 vs. $18.9 \%$ in the patients whose treatment was based on IC hemodynamic parameters in comparison with the patients treated on the basis of EBM. Moreover, similarly to Smith et al. [14], a statistically significant decrease of SBP and DBP was found in the final stage in the patients treated on the basis of IC parameters. However, Krzesiński et. al [15] found a reduction of blood pressure below 130/80: $36.6 \%$ vs. $23.5 \%$ in the group of patients treated on the basis of IC parameters in comparison with the patients treated on the basis of EBM. However, in the group of patients treated on the basis of EBM the blood pressure was found to drop below 140/90: $52.9 \%$ vs. $51.2 \%$ in comparison with the patients treated on the basis of IC parameters. Krzesinski et al. [15] showed that these differences also concerned the lower values of SBP and DBP. A statistically significant de- crease in these parameters was observed during the two stages of the study. However, no decrease of SBP and DBP was found at the final stage of the study. The above discrepancies may result from the obtained values of the SVRI parameter. Abdelhammeda et. al [16] observed that SVRI is higher in patients with hypertension in comparison with healthy subjects. Also, they indicated that the higher the value of hypertension, the higher the values of SVRI. Therefore, SVRI significantly affects the values of blood pressure. Both Smith et al. [14] as well as the authors of this paper obtained a significant decrease of SVRI at the final stage of the study. However, Krzesiński et. al [15] did not obtain a statistically significant decrease of SVRI at any stage of the study.

The above results indicate that the method of impedance cardiography aids the treatment and monitoring of hypertension [17]. This method allows for the individualized treatment of each patient on the basis of hemodynamic parameters, facilitating the choice of the optimal treatment regimen or its modification by effective changes of doses and drug combinations. Owing to this method, the values of blood pressure may be significantly decreased, which in turn may lead to lower risk of cardiovascular complications and related deaths $[14,18-20]$.

\section{Conclusions}

Impedance cardiography allows for the non-invasive, repeatable and precise monitoring of hypertension treatment. Moreover, therapeutic treatment based on this method guarantees a significant reduction of blood pressure and the choice of the most effective treatment strategy.

Source of funding: This work was funded by the Projekt Młody Naukowiec nr MNmb 250.

Conflict of interest: The authors declare no conflict of interests.

\section{References}

1. Marcinkowska E, Manitius J. Nadciśnienie tętnicze - od rozpoznania do leczenia. Fam Med Prim Care Rev 2005; 7(2): 283$-297$.

2. Polakowska M, Piotrowski W. Czynniki socjoekonomiczne a występowanie nadciśnienia tętniczego na wsi i w mieście. Badanie WOBASZ. Med Ogólna 2010; 16(45): 2.

3. Zdrojewski T, Rutkowski M, Bandosz P, et al. Prevalence and control of cardiovascular risk factors in Poland. Assumptions and objectives of the NATPOL 2011 Survey. Kardiol Pol 2013; 71(4): 381-392.

4. Cutler JA, Sorlie PD, Wolz M, et al. Trends in hypertension prevalence, awareness, treatment, and control rates in United States adults between 1988-1994 and 1999-2004. Hypertension 2008; 52(5): 818-827.

5. Kearney PM, Whelton M, Reynolds K, et al. Global burden of hypertension: analysis of worldwide data. Lancet 2005; 365(9455): 217-223.

6. Mancia G, De Backer G, Dominiczak A, et al. 2007 Guidelines for the Management of Arterial Hypertension: The Task Force for the Management of Arterial Hypertension of the European Society of Hypertension (ESH) and of the European Society of Cardiology (ESC). J Hypertens 2007; 25(6): 1105-1187.

7. Krzesiński P, Gielerak G, Kowal J. Impedance cardiography - a modern tool for monitoring therapy of cardiovascular diseases. Kardiol Pol 2009; 67: 65-71.

8. Sanidas EA, Grammatikopoulos K, Anastasiadis G, et al. Thoracic fluid content and impedance cardiography: a novel and promising noninvasive method for assessing the hemodynamic effects of diuretics in hypertensive patients. Hellenic J Cardiol 2009; 50(6): 465-471.

9. Siebert J. Kardiografia impedancyjna. Gdańsk: Via Medica; 2007: 48.

10. Sodolski T, Kutarski A. Impedance cardiography: a valuable method of evaluating haemodynamic parameters. Cardiol J 2007; 14(2): 115-126.

11. Ventura HO, Taler SJ, Strobeck JE. Hypertension as a hemodynamic disease: the role of impedance cardiography in diagnostic, prognostic, and therapeutic decision making. Am J Hypertens 2005; 18(2 Pt. 2): 26S-43S.

12. Alfie J, Galarza C, Waisman G. Noninvasive hemodynamic assessment of the effect of mean arterial pressure on the amplitude of pulse pressure. Am J Hypertens 2005; 18(2 Pt. 2): 60S-64S.

13. Ferrario $\mathrm{CM}$, Basile J, Bestermann $\mathrm{W}$, et al. The role of noninvasive hemodynamic monitoring in the evaluation and treatment of hypertension. Ther Adv Cardiovasc Dis 2007; 1(2): 113-118.

14. Smith RD, Levy P, Ferrario CM. Value of noninvasive hemodynamics to achieve blood pressure control in hypertensive subjects. Hypertension 2006; 47: 771-777.

15. Krzesiński P, Gielerak G, Kowal J, et al. Usefulness of impedance cardiography in optimisation of antihypertensive treatment in patients with metabolic syndrome: a randomised prospective clinical trial. Kardiol Pol 2012; 70(6): 599-607.

16. Abdelhammed Al, Smith RD, Levy P, et al. Noninvasive hemodynamic profiles in hypertensive subjects. Am J Hypertens 2005; 18: 51S-59S. 
17. Xiajuan Z, Ding D, Yanyan H, Zhen H. Impedance cardiographic hemodynamic variables and hypertension in elderly Han residents. Ups J Med Sci 2013; 118(2): 80-86.

18. Rada MA, Cuffaro PE, Galarza CR, et al. Predictive value of non-invasive hemodynamic measurement by means of impedance cardiography in hypertensive subjects older than 50 years of age. Clin Exp Hypertens 2014; 36(5): 280-284.

19. Taler SJ. Individualizing antihypertensive combination therapies: clinical and hemodynamic considerations. Curr Hypertens Rep 2014; 16(7): 451.

20. Krzesiński P, Gielerak G, Kowal J, et al. A „patient-tailored” treatment of hypertension with use of impedance cardiography: a randomized, prospective and controlled trial. Med Sci Monit 2013; 19: 242-250.

Address for correspondence:

Katarzyna Panasiuk-Kamińska, MD, PhD

Katedra i Zakład Medycyny Rodzinnej UM

ul. Langiewicza $6 \mathrm{~A}$

20-032 Lublin

Polska

Tel.: +48 81 524-78-56

E-mail: panasiuk.katarzyna@gmail.com

Received: 29.03.2016

Revised: 08.06.2016

Accepted: 14.06.2016 